\title{
A Study of Isothermal Curing of PMI Using DMA
}

\author{
Jing Zhang, Rui Ye, Jun Zou, Jijun Tang, and Hongliang Wang \\ School of Materials Science and Engineering, Jiangsu University of Science and Technology, Zhenjiang, Jiangsu 212000, China \\ Correspondence should be addressed to Jing Zhang; 82618354@qq.com
}

Received 12 December 2014; Revised 3 June 2015; Accepted 8 June 2015

Academic Editor: Somchai Thongtem

Copyright (C) 2015 Jing Zhang et al. This is an open access article distributed under the Creative Commons Attribution License, which permits unrestricted use, distribution, and reproduction in any medium, provided the original work is properly cited.

\begin{abstract}
The isothermal curing of polymethacrylimide (PMI) is studied through the use of dynamic mechanical analysis (DMA). Based on the growth rate of measured dynamic mechanical property, the relative conversion is defined to investigate the evolution of storage modulus $E^{\prime}$ at different curing temperatures. Hsich's nonequilibrium thermodynamic fluctuation theory, Avrami equation, and isoconversional methods are used to analyze isothermal cure kinetics of PMI. The results show that there are different increase modes of $E^{\prime}$ at low temperature range and high temperature range, respectively. In low temperature range, the relative conversion curves include a transitional stage which is found to be strongly frequency-dependent, but this stage is not observed in the relative conversion curve in high temperature range. During the isothermal curing process, the relative evolution of $E^{\prime}$ can be described by Hsich's nonequilibrium thermodynamic fluctuation theory and Avrami equation. Moreover, the values and evolutions of activation energy are different in two temperature ranges, which suggest that the curing mechanism probably has changed.
\end{abstract}

\section{Introduction}

Polymethacrylimide (PMI) is a kind of high-performance plastic foam, which was developed by a German company, Degussa, in 1972. It is widely used in the payload fairings and the interstage section of the Delta II satellite launch vehicle, the front end of the $E 4$ Shinkansen high speed train of Japanese railway, space electronic antenna devices, the current Ferrari Formula 1 race cars, and so on. The broad applications are owed to its superior material performance such as high strength-to-density ratio, 100\% closed cellular structure, higher levels of heat resistance and strength, good flame retardant properties, and attractive mechanical properties [1-4].

PMI is a kind of thermosetting polymeric foam with glutarimide rings in molecular structures [5]. It is traditionally prepared by heat treatment of block copolymers of acrylonitrile (AN) and methacrylic acid (MAA) in the presence of various foaming agents [5-7]. Since PMI has been invented, it has been studied by several authors with focuses such as preparation methods [5-8], properties [1], cellular structures [9], and applications $[1,3]$. However, there are few studies on the cure kinetics of PMI. The fact is that, during the heat treatment, foam process and curing process go on at the same time to generate homogeneous structures which provide stable material properties and then a stable service life. Therefore, it is necessary to study the curing mechanism in order to master the proper time for curing and foaming processes and then achieve desirable properties.

The cure kinetics have been an academic research topic for many years; various methods have been reported for describing the cure kinetics of thermosetting resins [10-15]. Avrami theory is one of the methods. It is originally used to describe the kinetic process of polymer crystallization. However, cross-linking lead to many molecular aggregates or high-molecular-weight particles during an infinite network formation [16]. Lu et al. [17] consider that, in a broad sense, crystallization can be considered as a physical form of crosslinking, and in some aspects the behavior of amorphous cross-linked polymers at a higher degree of curing reaction is similar to that of crystallization. Therefore, it is possible to predict the curing process of thermosetting resins through using Avrami equation. It has been used to study the cure kinetics of epoxy resins $[16,18,19]$. Isoconversional method is another approach applied to study the cure kinetics, which reveals the variations in the reaction mechanism which are accompanied by the changes in activation energy. They 


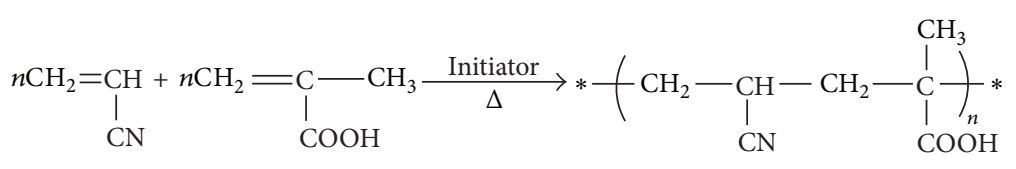

SCHEME 1

have been used to study the curing of epoxy resin and polyurethane systems $[13,20-22]$.

Traditionally, the common chemical analysis techniques attempting to study the curing process are Fourier transform infrared spectroscopy (FTIR) $[23,24]$ and differential scanning calorimetry (DSC) $[25,26]$ which detect the degree of the conversion of reactive groups and they have been used in previous curing researches [27-29]. As literatures [30-36] have reported, the curing process of PMI involves a series of complicated reactions including cross-linking. As thermosetting resin, once the cross-linking forms, PMI will not be softened and melted. The sensitivity and function of FTIR and DSC are much reduced at the last curing stage due to the increased consumption of reactive groups $[37,38]$, whereas dynamic mechanical analysis (DMA) can monitor the variation of dynamic mechanical properties during the curing process with high precision. In technical literatures [39-44], DMA is mainly used in measuring the gel point and the glass transition temperature during curing process of thermosetting resins. It is hardly preferred to study curing process based on dynamic mechanical properties. In this paper, DMA is employed to study the isothermal curing process of PMI.

The work presented in this paper focuses on the changes of dynamic mechanical properties of PMI during isothermal curing process and the growth mode of the relative conversion which is defined based on the growth rate of dynamic mechanical properties at different isothermal temperatures. Furthermore, cure kinetics analysis is developed by Hsich's nonequilibrium thermodynamic fluctuation theory, Avrami equation, and the isoconversional methods. The results can provide basis for researching curing reaction characteristic and the forming technology of PMI.

\section{Experimental}

2.1. Sample Preparation. PMI specimens are prepared in two steps. A mixture of $110 \mathrm{~g}$ of AN, $90 \mathrm{~g}$ MAA, $1 \mathrm{~g}$ azobisisobutyronitrile (AIBN), and $3 \mathrm{~g}$ acrylamide (AM) is polymerized in a three-necked flask at the water-bath temperature of $65^{\circ} \mathrm{C}$ for 2 hours with a magnetic stirring rate of $150 \mathrm{r} / \mathrm{min}$ to ensure the mixture is well-mixed. Then, the mixture is injected into a chamber formed from two glass plates and an edge seal. The postpolymerization is performed for 72 hours at the waterbath temperature of $50^{\circ} \mathrm{C}$. Regular plates are obtained.

2.2. Test Method. The specimens are made in the form of rectangular strips having dimensions of $45.0 \times 10.0 \times 4.0 \mathrm{~mm}^{3}$ and measured by DMA with a free length of $40 \mathrm{~mm}$ at $180^{\circ} \mathrm{C}$, $185^{\circ} \mathrm{C}, 190^{\circ} \mathrm{C}, 195^{\circ} \mathrm{C}$, and $200^{\circ} \mathrm{C}$ in a three-point bending mode. (It is found experimentally that the curing process is

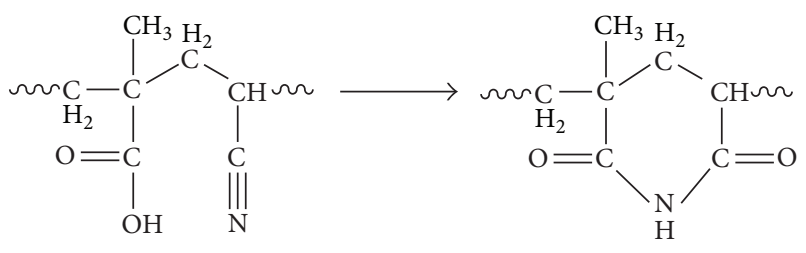

SCHEMe 2<smiles>[R]C(C)(C)C(N)=O</smiles><smiles>[R]C(C)(C)C(=O)NC(=O)C([R])(C)CCCCC([R])(CC)C(N)=O</smiles>

SCHEMe 3

slow and it takes a long time to react below $180^{\circ} \mathrm{C}$, while the specimens are scorched above $200^{\circ} \mathrm{C}$.) The experiments are performed with $0.1 \mathrm{~Hz}, 0.3 \mathrm{~Hz}, 1 \mathrm{~Hz}, 3 \mathrm{~Hz}$, and $10 \mathrm{~Hz}$ oscillation frequency and 80um amplitude. The parameters such as storage modulus $E^{\prime}$, loss modulus $E^{\prime \prime}$, and loss factor $\tan \delta$ are obtained from DMA curves.

\section{Principle of Chemical Reaction}

A series of chemical reactions may take place during the curing process.

Long chain molecular will be generated from the addition reaction between double bonds of AN and MAA. The reaction is shown in Scheme 1.

Chains of adjacent MAA and AN rearrange and glutarimide rings form resulting from imidization involving acid and nitrile units. It is the main reaction in curing process of PMI $[5,8]$. The reaction is shown in Scheme 2.

It has also been suggested that cross-linking reaction may take place during the curing process, including the crosslinking reaction of AM [30-34] and the intermolecular crosslinking reaction of MAA [35]. The deamination reaction of AM and other molecules is shown in Scheme 3 and dehydration reaction of AM and other molecules is shown 


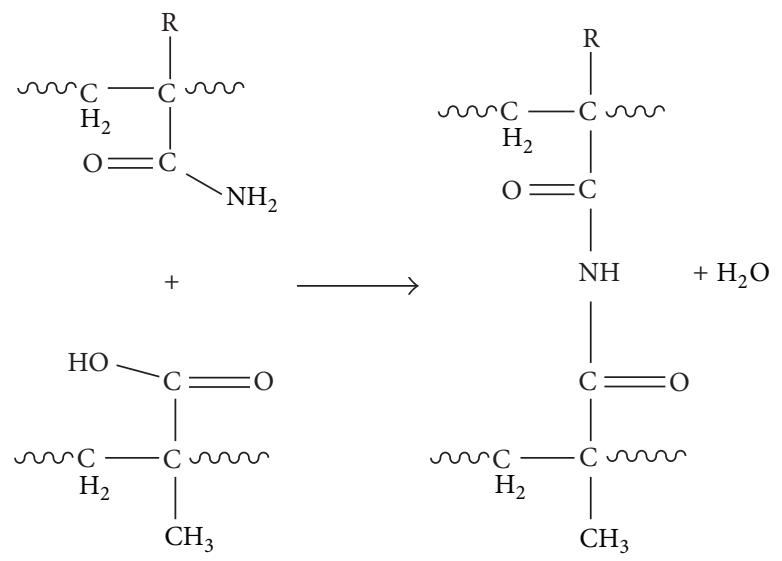

SCHEMe 4

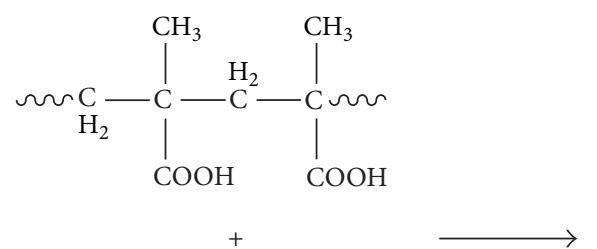<smiles>CC(C)(CC(C)(C)C(=O)O)C(=O)O</smiles><smiles>CCC(C)(CC(C)(C)C(=O)O)C(=O)O</smiles><smiles>CC(C)(CC(C)(C)C(=O)O)C(=O)O</smiles>

SCHEME 5<smiles>CCCCCCCCCC(C#N)CC(C#N)CC(C#N)CC(C#N)CC</smiles>

SCHEME 6

in Scheme 4. Scheme 5 shows the dehydration cross-linking reaction of MAA and adjacent molecules.

In addition, the intermolecular cross-linking of AN may form a cyclic polyimine structure frequently referred to as "ladder polymer" and the scheme is shown in Scheme 6 $[35,36]$.

\section{Results and Discussions}

4.1. Isothermal Curing Characterization of DMA. Figure 1 shows DMA isothermal measurements of PMI at $180^{\circ} \mathrm{C}$. (The timeline in Figure 1(a) is logarithmic coordinates and results are shown in Figure 1(b).) The change of dynamic mechanical properties could be divided into three stages. In the first stage, the test temperature increases from room temperature to $180^{\circ} \mathrm{C}$ rapidly, namely, heating stage. In this stage, $E^{\prime}$ and $E^{\prime \prime}$ decrease rapidly to the minimum. $\tan \delta$ initially increases and then decreases with forming a peak which corresponds to the rapid decline period of $E^{\prime}$ and $E^{\prime \prime}$. This stage could be due to the softening of PMI. In the second stage, $E^{\prime}$ initially undergoes a relatively slower increase process. It could possibly be ascribed to the imidization during the isothermal curing process of PMI (Scheme 2). So this slower increase period could be considered as the start of the reaction. Then, $E^{\prime}$ has an appreciable increase and spans three orders of magnitudes. In this period, the imidization reaction takes place and the formation of hexahydric imide rings is identified, while $E^{\prime \prime}$ increases rapidly to an equilibrium value after the emergence of a small peak. Meanwhile, there are two peaks on the curve of $\tan \delta$. The first peak (when time is $13.66 \mathrm{~min}$ ) which is relatively weak appears in the slow 


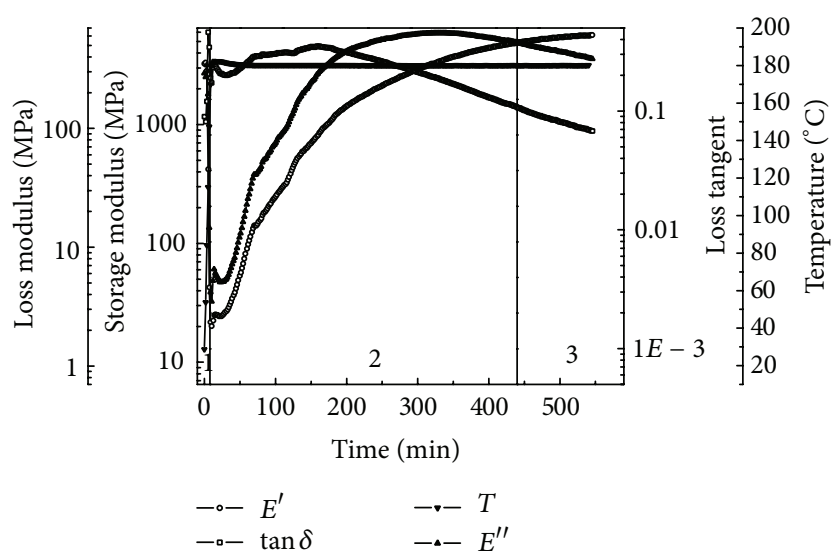

(a)

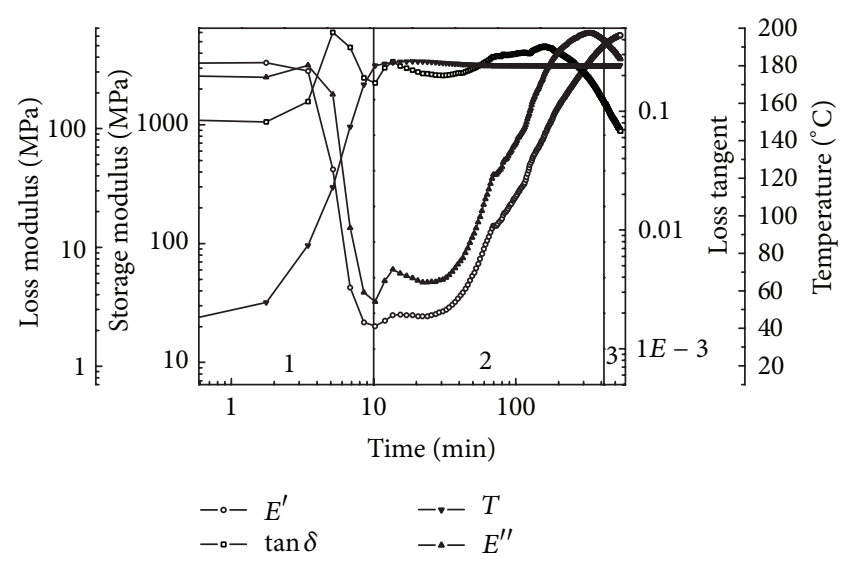

(b)

FIgURE 1: DMA isothermal measurements of PMI at $180^{\circ} \mathrm{C}$. The timeline in (a) is on normal scale and (b) is on log scale.

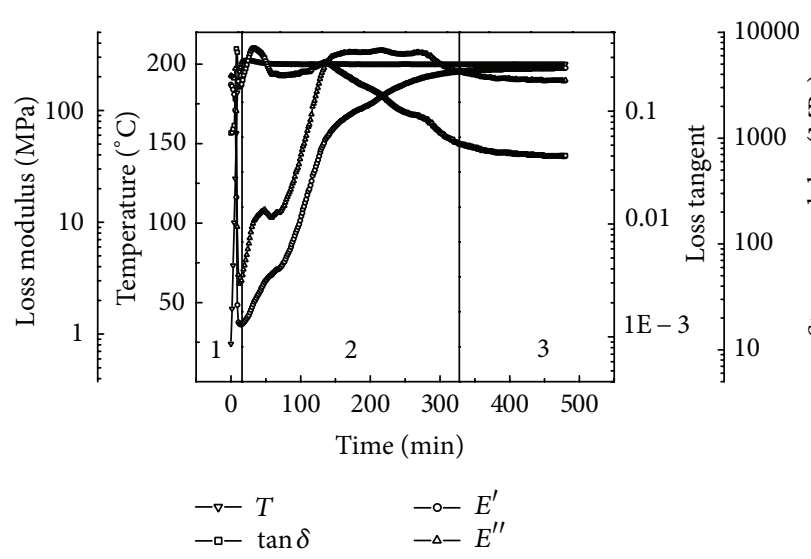

(a)

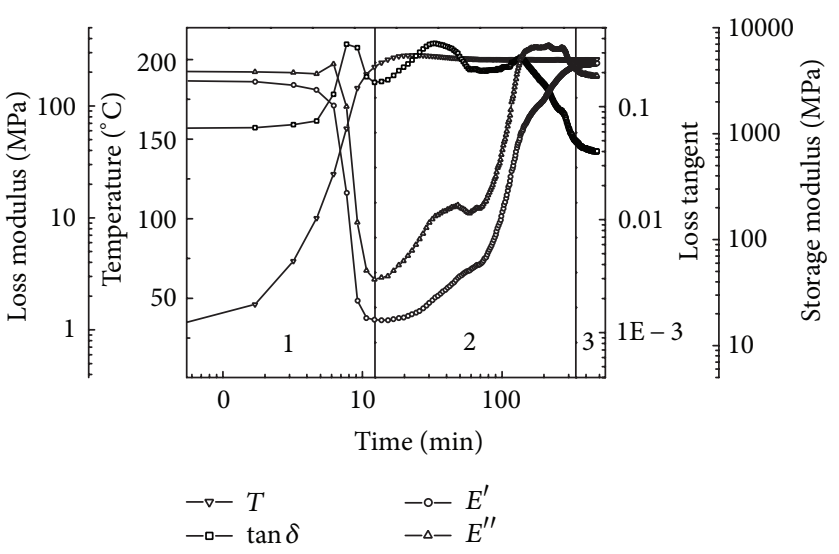

(b)

FIgURE 2: DMA isothermal measurements of PMI at $200^{\circ} \mathrm{C}$. The timeline in (a) is on normal scale and (b) is on log scale.

increase period of $E^{\prime}$; it may correspond to the cross-linking reaction (Schemes 3 6).

Nevertheless, the cross-linking is limited because of the low temperature. As a result, the corresponding peak is weak. The second peak (when time is $158 \mathrm{~min}$ ) appears in the rapid increase period of $E^{\prime}$, corresponding to the imidization reaction shown as in Scheme 1. In the third stage, the reaction goes into the final period when the variation of $E^{\prime}, E^{\prime \prime}$, and $\tan \delta$ tends to slow down and gradually reach balance. Thus, the isothermal curing process is over.

Figure 2 shows the isothermal curing curves of PMI at $200^{\circ} \mathrm{C}$. During the second stage, the rapid increase periods of $E^{\prime}$ and $E^{\prime \prime}$ are significantly faster than the ones at $180^{\circ} \mathrm{C}$ because high temperature is more conducive to curing process. In this period, the $\tan \delta$ curve still has two peaks. The first peak (when time is 33.2 minutes) is stronger than that at $180^{\circ} \mathrm{C}$. This is due to the cross-linking reactions which are more active at the high temperature of $200^{\circ} \mathrm{C}$. The second peak (when time is $135 \mathrm{~min}$ ) is more significant than that at $180^{\circ} \mathrm{C}$, because high temperature is beneficial to imide reaction.
In order to describe the growth of dynamic mechanical properties of PMI during curing process quantitatively, the relative mechanical conversion is indicated as follows [45]:

$$
\alpha^{\prime}=\frac{\left(E_{t}^{\prime}-E_{0}^{\prime}\right)}{\left(E_{\infty}^{\prime}-E_{0}^{\prime}\right)}
$$

where $\alpha^{\prime}$ is the relative conversion and $E_{t}^{\prime}, E_{0}^{\prime}$, and $E_{\infty}^{\prime}$ present the storage modulus at a time $t$, at the onset (uncured PMI) and upon completion of the reactive process (fully cured PMI), respectively. The start point of the second stage of $E^{\prime}$ is regarded as the onset time and the final equilibrium value is regarded as the ending point of curing process.

The relative mechanical conversion curves at $180^{\circ} \mathrm{C}$, $185^{\circ} \mathrm{C}, 190^{\circ} \mathrm{C}, 195^{\circ} \mathrm{C}$, and $200^{\circ} \mathrm{C}$ are shown in Figure 3, respectively. Comparing the curves at different temperatures, as the isothermal curing temperatures increase, the growth rate of $\alpha^{\prime}$ accelerates and the major increase stage advances. The growth mode of $\alpha^{\prime}$ is divided into two ranges: the high temperature range $\left(190^{\circ} \mathrm{C} \sim 200^{\circ} \mathrm{C}\right)$ and the low temperature range $\left(180^{\circ} \mathrm{C} \sim 190^{\circ} \mathrm{C}\right)$. In the low temperature range, the 


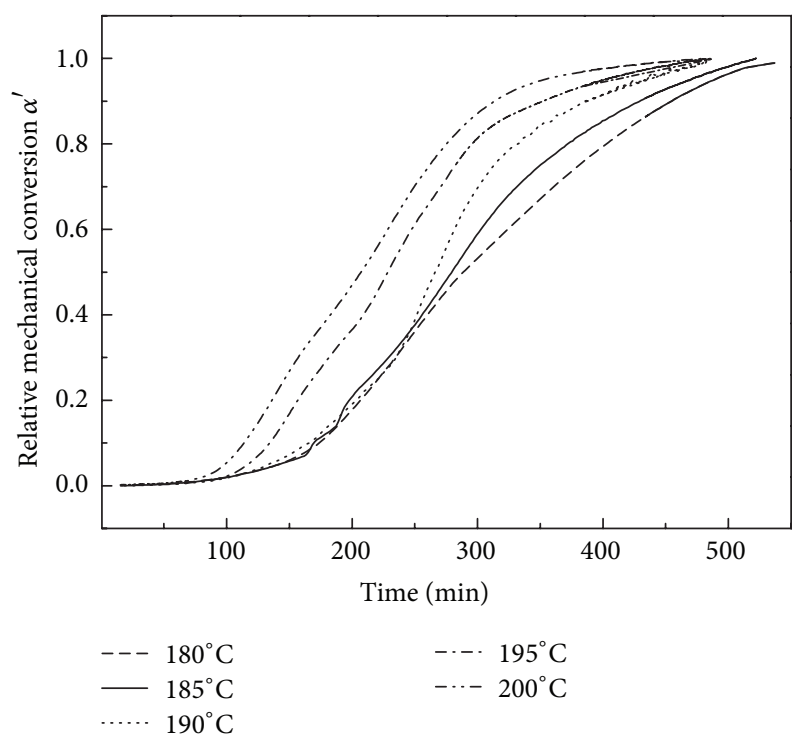

FIGURE 3: Relative mechanical conversion curves of PMI at different temperatures.

increase of $\alpha^{\prime}$ undergoes a transition stage with a relatively slower change. However, the $\alpha^{\prime}$ curves increased directly and rapidly in the high temperature range and the transition stage that existed in the low temperature range is not observed. It suggests that the growth mechanism of $E^{\prime}$ is different during two temperature ranges.

DMA is carried out to test the multiple frequency isothermal curing process of PMI. The $\alpha^{\prime}$ curves under different temperatures and frequencies based on DMA data are analyzed to study the inner cause and mechanism which may result in the transition stage difference existing between different temperature ranges. As shown in Figure 4 , at $180^{\circ} \mathrm{C}$, the $\alpha^{\prime}$ curves of different frequencies coincide at prophase and anaphase, while they separate in the middle transition stage and the values of $\alpha^{\prime}$ corresponding to the same time reduce as frequencies decrease, which shows the frequency correlation. What is more, the emergence of the peaks on the $E^{\prime \prime}$ curves gradually delays as the frequencies decrease. However, as can be seen, the $\alpha^{\prime}$ curves of different frequencies roughly coincide together at $200^{\circ} \mathrm{C}$, which are independent of frequency. The noticeable frequency correlation at $180^{\circ} \mathrm{C}$ is not observed. What is more, the $E^{\prime \prime}$ curves of different frequencies are well coincident and do not show the delay phenomena at $200^{\circ} \mathrm{C}$.

As thermosetting resin, the isothermal curing process of PMI demonstrates that there is a maximum glass transition temperature $T_{g, \infty}$ below which the glass transition temperature $T_{g}$ will increase with the increasing of curing degree during the curing process. Thus, the system will enter into the glassy state and the reaction rate has a sharp decline when the glass transition temperature $T_{g}$ increases near the curing temperature $T_{c}$. A paper has pointed out that glass transition would take place in the range of $\left|T_{g}-T_{c}\right|=20 \sim$ $30^{\circ} \mathrm{C}$ [45]. The $T_{g}$ of PMI is $176.57^{\circ} \mathrm{C}$ (as shown in Figure 5). Frequency has an effect on the glass transition. The higher the frequency, the earlier the glass transition and the lower the glass transition temperature. Therefore, this explains why the frequency-dependent regions exist on the $\alpha^{\prime}$ curves and $E^{\prime \prime}$ curves during curing process of PMI. At low temperatures, glass transition takes place on a low degree of curing and the system completely enters into the glassy state at the last stage of cure. However, at high temperatures, glass transition takes place later when curing degree becomes high and only small part enters into the glassy state at anaphase. As a result, the $\alpha^{\prime}$ curves at high temperature do not show a significant correlation with frequency.

4.2. Curing Kinetics Analysis. Hsich has derived the curing kinetic equation of mechanical property diversification during curing process from relaxation phenomena in materials by the nonequilibrium thermodynamic fluctuation theory; it may be represented as follows [46]:

$$
\frac{P_{\infty}-P(t)}{P_{\infty}-P_{0}}=\exp \left[-\left(\frac{t}{\tau}\right)^{\beta}\right]
$$

where $P$ is the mechanical property of the test system, $\beta$ is the chemical relaxation spectrum width, and $\tau$ is the chemical relaxation time.

Avrami equation is derived by the thermodynamic method based on polymer crystallization process. In its classical form it can be expressed as [19]

$$
1-\alpha=\exp \left[-k t^{n}\right]
$$

where $k$ is a temperature dependent kinetic constant, $\alpha$ is the relative degree of cure, and $n$ is the Avrami exponent that is a reflection of nucleation and growth mechanism. However, if $P$ is replaced by $E^{\prime}$ and combining with (1), (2) can be alternatively written as

$$
1-\alpha^{\prime}=\exp \left[-\left(\frac{t}{\tau}\right)^{\beta}\right]
$$

It is evident that Hsich's nonequilibrium thermodynamic fluctuation theory and Avrami equation have the same format by delimiting the relative conversion $\alpha^{\prime}$. Applying logarithmic properties to both sides of (3), the following equation could be obtained:

$$
\ln [-\ln (1-\alpha)]=\ln k+n \ln t .
$$

The modified Avrami equation could be used to get the kinetic parameters from the cure curves at different temperatures. A best fit line of the plot of $\ln [-\ln (1-\alpha)]$ versus $\ln t$ will provide parameter $n$ from the slope and $k$ from the intercept.

The $\ln \left[-\ln \left(1-\alpha^{\prime}\right)\right]-\ln t$ curves of PMI at different isothermal temperatures are presented in Figure 6. The curves could be divided into two segments according to different slopes. The kinetic parameters obtained by the Avrami theory are listed in Table 1.

Obviously, the values of $n_{2}$ are less than those of $n_{1}$ at different temperatures. Because $n$ is the reflection of growth mechanism, it is possible to judge that the growth mechanism of $\alpha^{\prime}$ changes during curing process. 


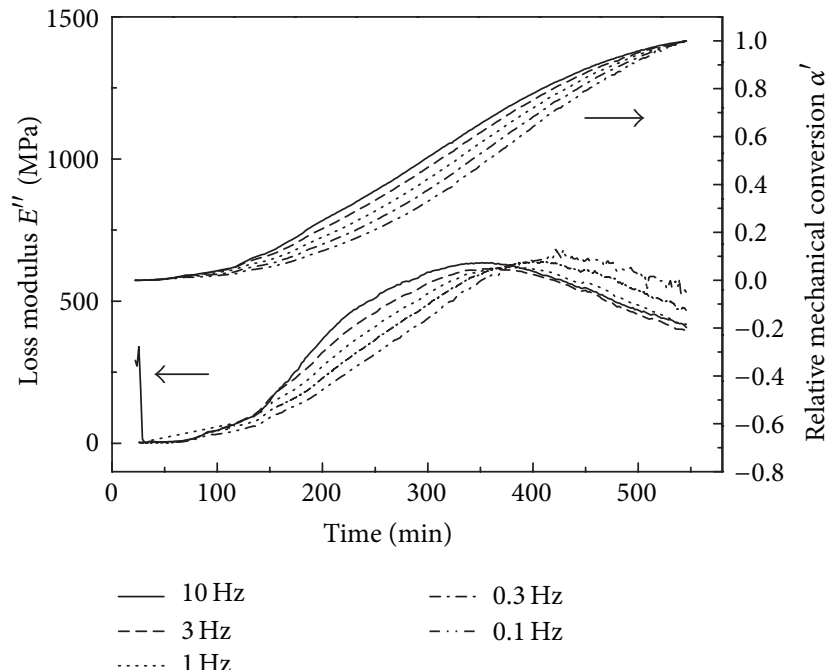

(a) $180^{\circ} \mathrm{C}$

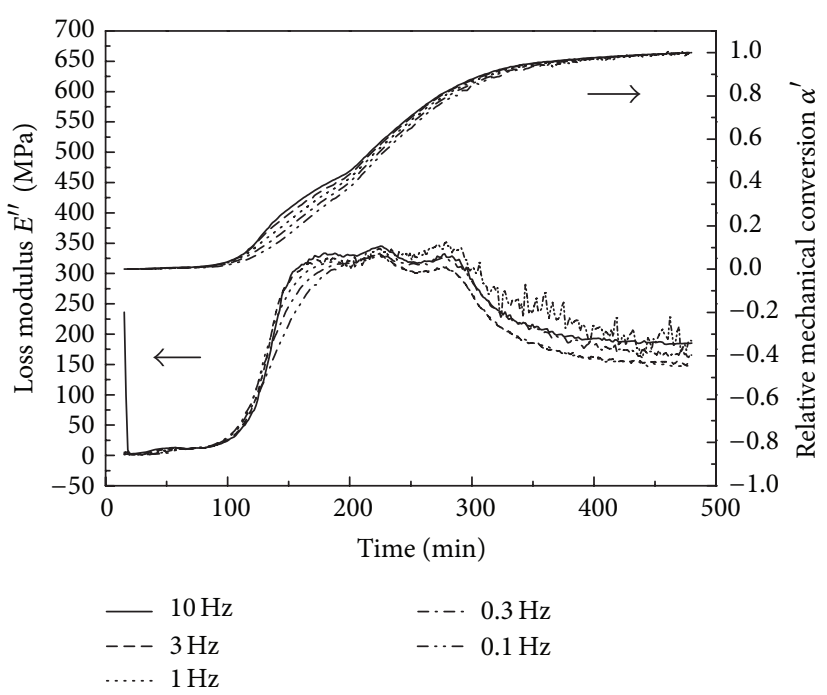

(b) $200^{\circ} \mathrm{C}$

FIGURE 4: Multiple frequency relative mechanical conversion curves and loss modulus curves of PMI.

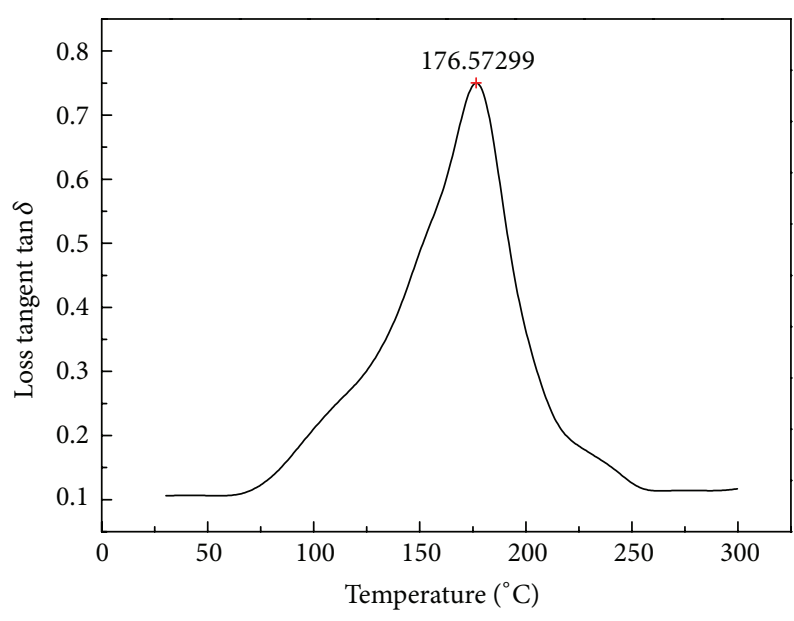

FIgure 5: Loss tangent $\tan \delta$ curves of PMI.

TABLE 1: Fitting results to the growth index $n$ of PMI at different temperature.

\begin{tabular}{lccccc}
\hline$T /{ }^{\circ} \mathrm{C}$ & 180 & 185 & 190 & 195 & 200 \\
\hline$n_{1}$ & 7.56769 & 6.20696 & 7.88197 & 7.33638 & 7.93085 \\
$n_{2}$ & 2.66192 & 3.12797 & 3.3849 & 3.26904 & 3.24101 \\
\hline
\end{tabular}

Note: the subscripts 1 and 2 denote segments 1 and 2 in Figure 6.

Figure 7 shows the fitting results of isothermal $\alpha^{\prime}$ curves of PMI by Avrami equation. It could be clearly seen that the fitting curves fit well with the experimental curves approximately, indicating that it is feasible for Avrami equation model to apply on the analysis of PMI curing process. Avrami equation is often used to study the crystallization process of crystal, so it could be inferred that the relative evolution of $E^{\prime}$ during PMI isothermal curing process is similar to the crystallization process of high polymer.

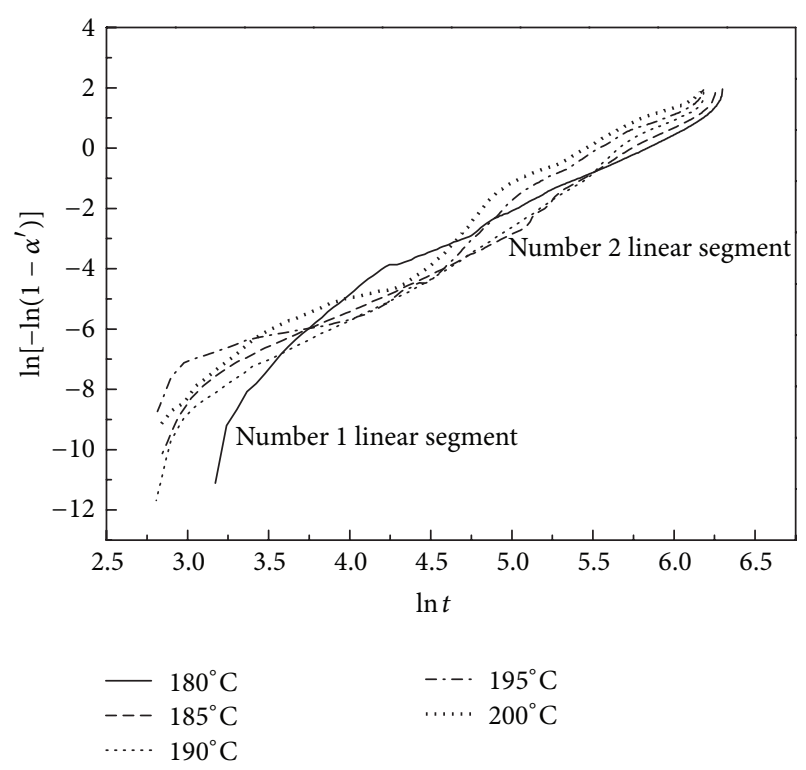

Figure 6: The $\ln \left[-\ln \left(1-\alpha^{\prime}\right)\right]-\ln t$ curves of PMI at different isothermal temperatures.

It is known that the correlation between $k$ and $T$ can be shown as the following empirical equation [37]:

$$
k^{1 / n}=k_{0} \exp \left[-\frac{E}{R T}\right],
$$

where $E$ is the activation energy, $T$ is the absolute temperature of cure, $R$ is the universal gas constant, and $n$ the Avrami exponent. Applying logarithmic properties to both sides of (6), the modified equation is obtained from which the activation energy can be calculated:

$$
\frac{1}{n} \ln k=\ln k_{o}-\frac{E}{R T} .
$$




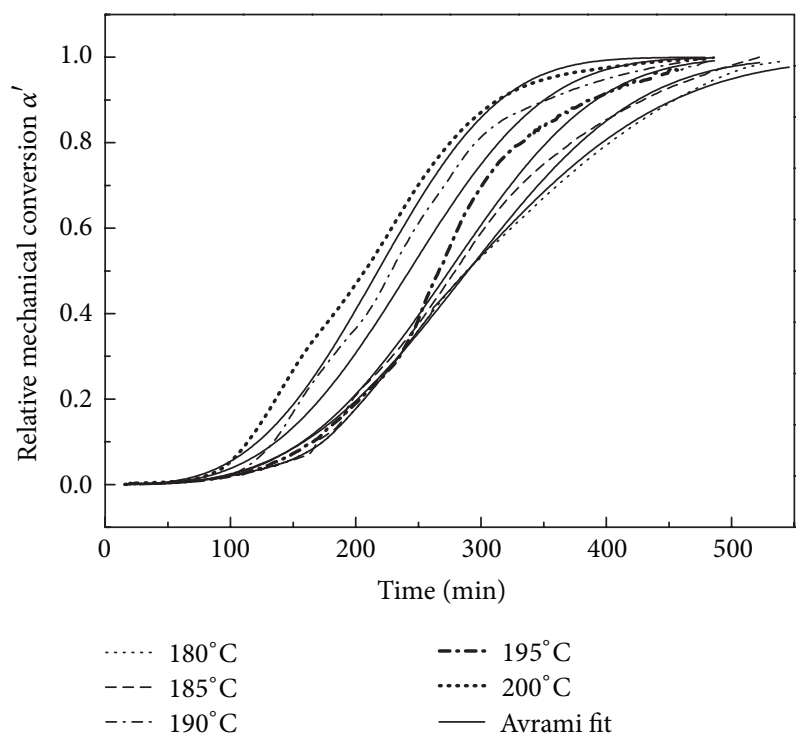

FIGURE 7: Fitting results of isothermal $\alpha^{\prime}$ curves of PMI by Avrami equation.

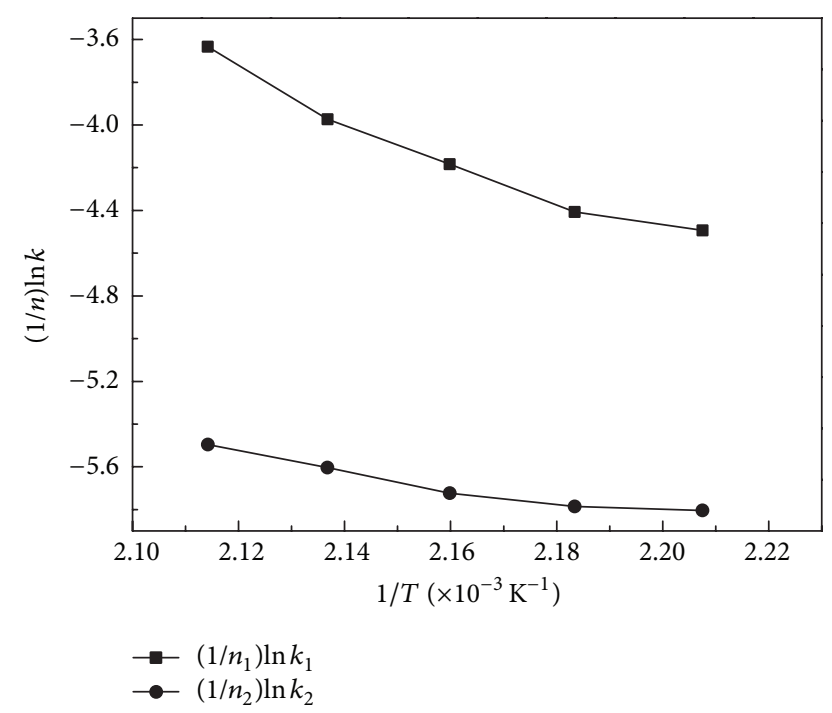

Figure 8: $(1 / n) \ln k-1 / T$ relationship for the linear segments of the $\ln \left[-\ln \left(1-\alpha^{\prime}\right)\right]-\ln t$ curves of PMI.

Figure 8 shows the $(1 / n) \ln k-1 / T$ relationship for the linear segments of the $\ln \left[-\ln \left(1-\alpha^{\prime}\right)\right]-\ln t$ curves which could be divided into two temperature ranges including $180^{\circ} \mathrm{C} \sim 190^{\circ} \mathrm{C}$ and $190^{\circ} \mathrm{C} \sim 200^{\circ} \mathrm{C}$, respectively. It is clearly seen in Figure 7 that the slopes in two temperature ranges are different; in other words, the fact activation energies are different which indicates that the growth mechanism of $\alpha^{\prime}$ changes in different temperature ranges. The parameters $k$ and $E$ are listed in Table 2. The values of $k$ in high temperature range are larger than the corresponding values in low temperature range. The reason for this difference may be that the higher temperature is more conducive to the reaction within limits, while the activation energies in high temperature range are higher than those in low temperature
TABLE 2: Activation energy of the evolution of $\alpha^{\prime}$ during the cure process of PMI by Avrami equation.

\begin{tabular}{lcccc}
\hline Temperature $/{ }^{\circ} \mathrm{C}$ & $k_{0,1} / \mathrm{s}^{-1}$ & $E_{1} /\left(\mathrm{KJ} \cdot \mathrm{mol}^{-1}\right)$ & $k_{0,2} / \mathrm{s}^{-1}$ & $E_{2} /\left(\mathrm{KJ} \cdot \mathrm{mol}^{-1}\right)$ \\
\hline $180 \sim 190$ & $1.8 \times 10^{4}$ & 53.99 & 0.12 & 13.96 \\
$190 \sim 200$ & $2.7 \times 10^{9}$ & 99.81 & 152.98 & 41.39 \\
\hline
\end{tabular}

Note: the subscripts 1 and 2 denote segments 1 and 2 in Figure 5.

range. The possible reason for this abnormal phenomenon is that the cross-linking reaction is difficult to occur, leading to a high activation energy in this range. In the same temperature range, the values of $k$ on the first segment are larger than the corresponding values on the second segment. This result is due to the transformation from chemical control mechanism at prophase to diffusion controlled mechanism at anaphase. The decrease of activation energy of thermosetting system after obeying the diffusion controlled mechanism has been investigated [46]. It is clearly shown in Table 2 that the activation energies on the first segment are higher than those on the second segment, which further indicates that the reaction at prophase obeys the diffusion controlled mechanism.

An alternative approach is the application of the modelfree isoconversional methods which allow for the evaluation of the activation energy as a function of the extent of the reaction, without assuming any kinetic model $[20,47,48]$. These methods including integral methods (Isoint methods) and differential methods (FR methods) shown in (8) and (9) are determined by the specific form of $\alpha$ in the basic equation [49]:

$$
\begin{array}{r}
\ln t_{\alpha, i}=\ln \left[\frac{g(\alpha)}{A}\right]+\frac{E_{\alpha}}{R T_{i}}, \\
\ln \left(\frac{d \alpha}{d t}\right)_{\alpha, i}=\ln \left[A_{\alpha} f(\alpha)\right]-\frac{E_{\alpha}}{R T_{i}},
\end{array}
$$

where $f(\alpha)$ is kinetic function which depends on the conversion degree, $A$ is the frequency factor, $t$ is the curing time, $E_{\alpha}$ is the activation energy at a constant $\alpha$ value, and $g(\alpha)$ is the integral form of $f(\alpha)$ just shown as follows:

$$
g(\alpha)=\int_{0}^{\alpha} \frac{d \alpha}{f(\alpha)}=A \int_{0}^{t \alpha} \exp \left(-\frac{E_{\alpha}}{R T(t)}\right) d t
$$

the subscript $i$ represents ordinal number of an experiment performed under constant temperature. It is the basic assumption of the isoconversional methods that the reaction rate at constant $\alpha$ value is only a function of the temperature. Therefore, the activation energy $\left(E_{a}\right)$ in $(8)$ could be determined from the slope of the plot of $\ln (t)$ versus $1 / T$, at constant $\alpha$ value. Similar method is used to calculate the $E_{a}$ in (9) from the slope of the plot of $\ln (d \alpha / d t)$ versus $1 / T$, at a constant $\alpha$ value. Vyazovkin has proposed that relative conversion rate could be used to calculate the activation energy when the isothermal curing reaction takes place below $T_{g, \infty}[50]$.

By applying the isoconversional methods to the DMA isothermal curing data, the relative mechanical conversion 
TABLE 3: The values of $R$ in Gauss fit.

\begin{tabular}{lccccc}
\hline$T /{ }^{\circ} \mathrm{C}$ & 180 & 185 & 190 & 195 & 200 \\
\hline$R$ & 0.982 & 0.979 & 0.992 & 0.982 & 0.973 \\
\hline
\end{tabular}

TABLE 4: Relative conversion $\alpha^{\prime}$ at the maximum rate of $\alpha^{\prime}$ of PMI at different isothermal temperatures in peak 1 and peak 2 .

\begin{tabular}{lccccc}
\hline$T /^{\circ} \mathrm{C}$ & 180 & 185 & 190 & 195 & 200 \\
\hline$\alpha^{\prime}$ peak 1 & 0.175 & 0.194 & 0.186 & 0.160 & 0.174 \\
$\alpha^{\prime}$ peak 2 & 0.542 & 0.561 & 0.576 & 0.588 & 0.574 \\
\hline
\end{tabular}

rate as a function of conversion at different temperatures is shown in Figure 9. Similar trend is observed in the range of $180^{\circ} \mathrm{C} \sim 190^{\circ} \mathrm{C}$ which is that there is a major peak at about 0.5 of $\alpha^{\prime}$ and a weak peak before that. However, the curves have a noticeable difference at the temperatures of $195^{\circ} \mathrm{C}$ and $200^{\circ} \mathrm{C}$. It is evident that two peaks appear on the curves implying the curing mechanism changes at high temperatures.

Because the curing mechanism changes as curing temperature increases, in order to identify the responsible reaction, peak separation is applied to the curve by Gauss fit method [51], just shown as in Figure 10. The coefficient of determination $R$ is a parameter to evaluate the goodness of fit. The closer the $R$ value is to 1 , the better the fit is. Table 3 shows the value of $R$ in Gauss fit; the values are all above 0.97; it suggests the Gauss fit is good. Peak separation result is shown in Figure 11 where Figure 11(a) shows the first peaks and Figure 11(b) shows the second peaks. As can be seen, both peak 1 and peak 2 gradually increase with increasing temperature. Table 4 shows the value of $\alpha^{\prime}$ corresponding to the maximum rate of $\alpha^{\prime}$ in peak 1 and peak 2 at different curing temperatures. It is noteworthy that the results are basically in agreement with the common assumption of the isoconversional methods.

It should be noted that the presence of the two peaks evidences that peak 2 is a reflection of imidization reaction which takes place at about 0.5 of $\alpha^{\prime}$ and peak 1 is a reflection of cross-linking reaction which has been shown in Schemes 3 5. In what follows, we would concentrate on peak 2 in order to study the curing process of PMI by isoconversional methods.

Figure 12 shows the activation energy curves of isothermal curing processes of PMI by isoconversional methods. Figure 12 is the evolution of activation energy obtained from Figure 11 during the curing process of PMI at different temperature ranges. It could be seen from Figure 12 that some values of the activation energy are negative when the value of $\alpha^{\prime}$ is less than 0.4 , which suggests that isoconversional methods are not applicable within this range. So the activation energies are calculated from 0.4 to 0.8 . Simultaneously, the half-peak width is determined by that and the peak separation result shown in Figure 11 coincides well with that. As seen from Figure 12, the linear relationships corresponding to the same $\alpha^{\prime}$ are different in different temperature ranges $\left(180^{\circ} \mathrm{C} \sim\right.$ $190^{\circ} \mathrm{C}$ and $190^{\circ} \mathrm{C} \sim 200^{\circ} \mathrm{C}$ ); that is to say, the activation energies are different. It could also be seen from Figure 13 that the

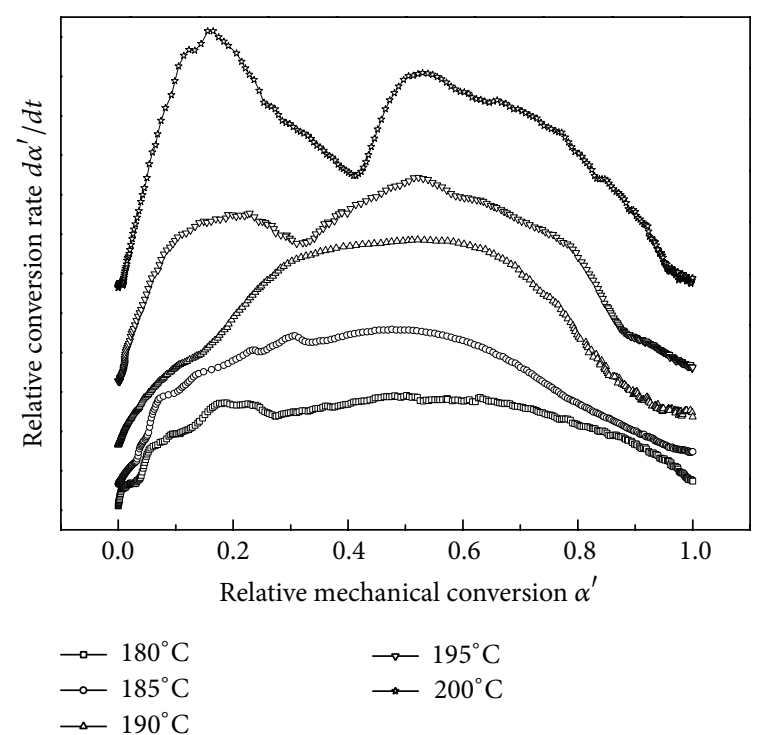

FIGURE 9: Relative mechanical conversion rate versus relative mechanical conversion of PMI.

activation energies corresponding to the same $\alpha^{\prime}$ are different in different temperature ranges. It further proves that the growth mechanism of $\alpha^{\prime}$ in different temperature ranges is different and the result is very near to that analyzed by Avrami equation.

In Figure 13, similar increase trends of activation energy analyzed by different isoconversional methods are observed and the slight difference of the specific trend and exact value are associated most probably with the derivation of different methods. However, the increase trends of activation energy in different temperature ranges have a noticeable difference. In low temperature range, the activation energies first increase and then decrease with the increasing of $\alpha^{\prime}$. This is probably because the system enters into the diffusion controlled period which leads to the decrease of activation energy. While it is possible that the system enters into the diffusion controlled period prematurely due to the cross-linking reaction on prophase, as a result, the activation energy decreases in high temperature range [46]. The result is in agreement with that analyzed by Avrami equation.

\section{Conclusion}

In summary, from the results presented above, we could obtain the following conclusions. (1) The isothermal curing curves of PMI could be divided into three stages and the curves at $180^{\circ} \mathrm{C}$ and $200^{\circ} \mathrm{C}$ are different: at the second stage, the growth rate of $E^{\prime}$ and $E^{\prime \prime}$ in the rapid mounting periods at $200^{\circ} \mathrm{C}$ is significantly faster than that at $180^{\circ} \mathrm{C}$. The $\tan \delta$ curves at $180^{\circ} \mathrm{C}$ and $200^{\circ} \mathrm{C}$ are similar in having two peaks, but with obvious differences in their peaks. Compared with the two peaks at $180^{\circ} \mathrm{C}$, the first peak is significantly elevated and the second peak is more obvious at $200^{\circ} \mathrm{C}$. (2) It is found that the increase mode of $E^{\prime}$ under low temperature $\left(180^{\circ} \mathrm{C} \sim\right.$ $\left.190^{\circ} \mathrm{C}\right)$ and high temperature $\left(190^{\circ} \mathrm{C} \sim 200^{\circ} \mathrm{C}\right)$ is different. The 

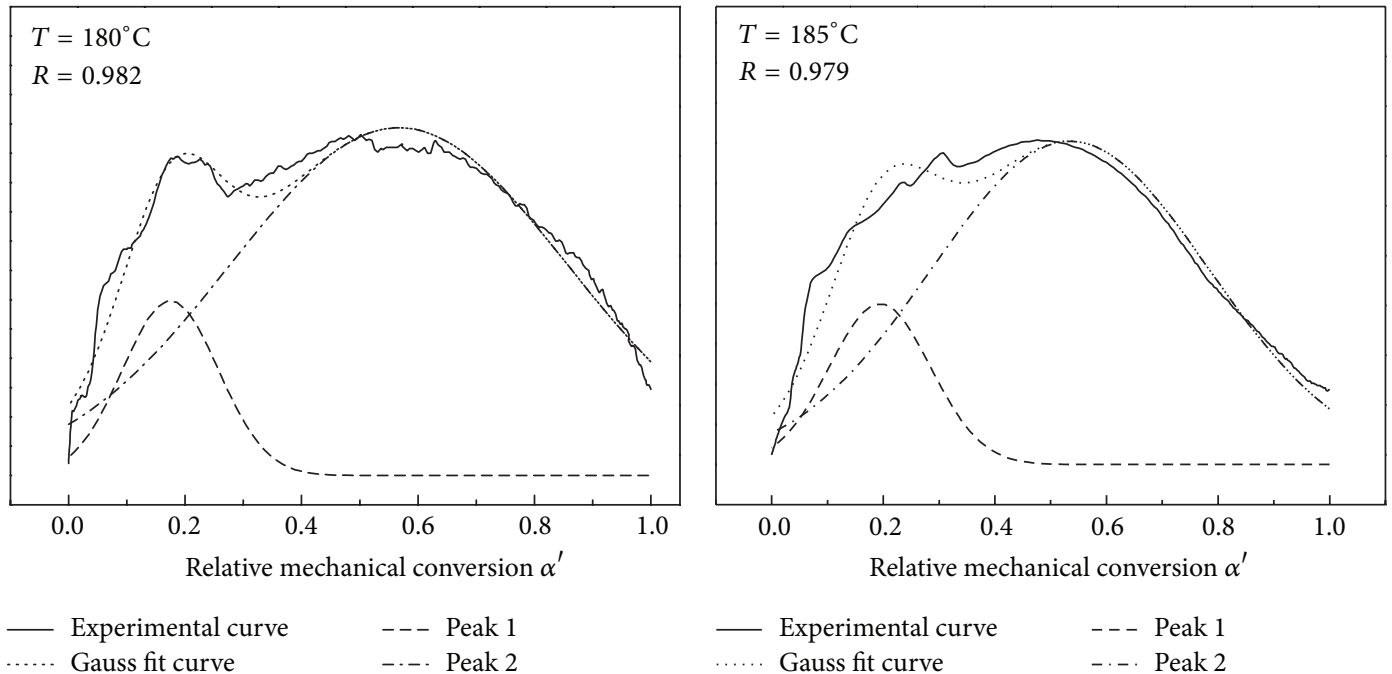

(a)
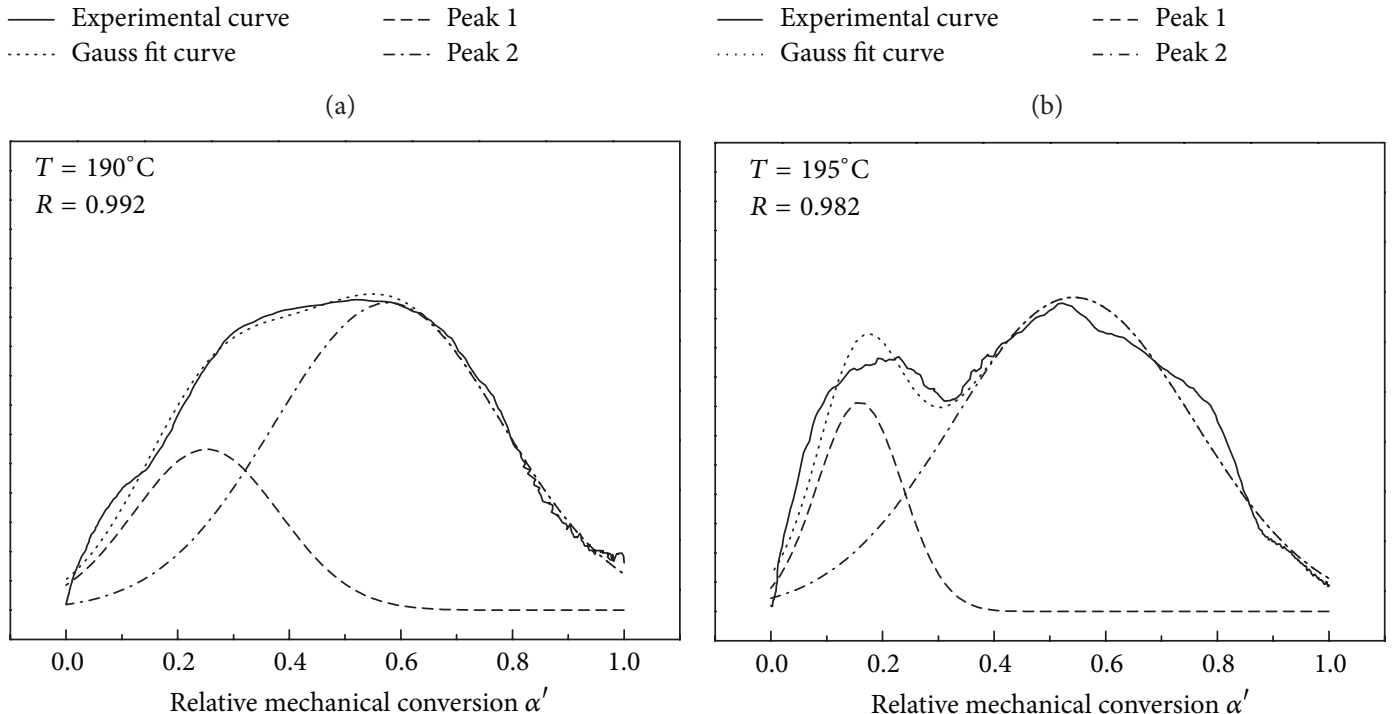

_ Experimental curve

--- Peak 1

-.-. Peak 2

- Experimental curve

--- Peak 1

Gauss fit curve

(c)

(d)

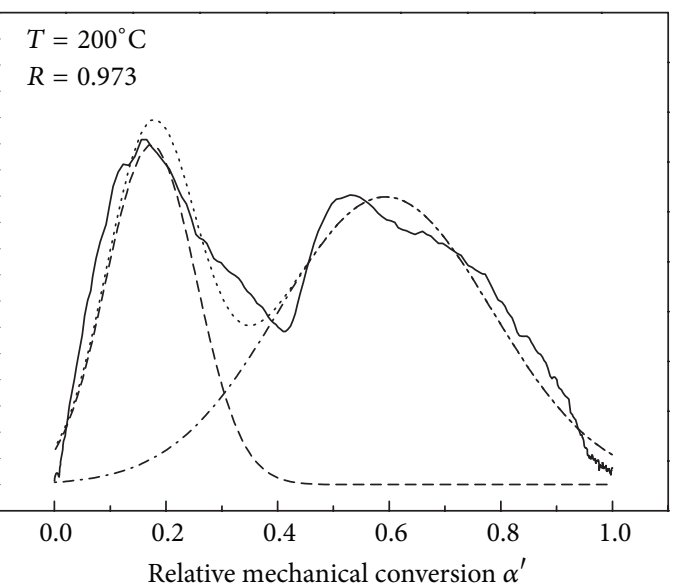

$\begin{array}{ll}\text { - Experimental curve } & \text {--- Peak } 1 \\ \text {..... Gauss fit curve } & \text {-.-. Peak } 2\end{array}$

(e)

FIGURE 10: Gauss fit curves at temperatures of $180 \sim 200^{\circ} \mathrm{C}$. 


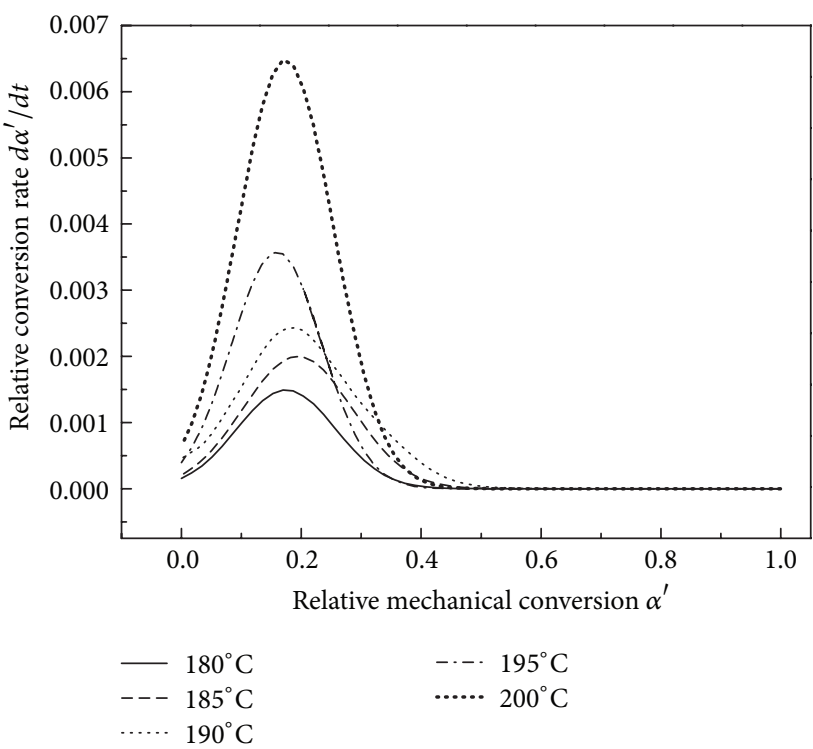

(a)

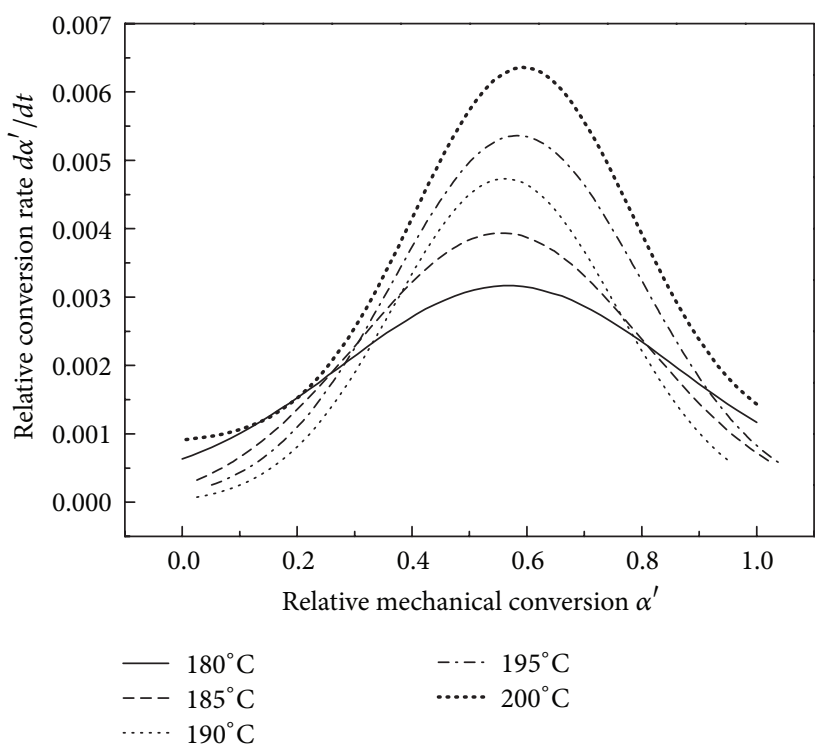

(b)

FIGURE 11: Peak separation result of relative mechanical conversion rate as a function of relative mechanical conversion of PMI, where (a) is peak 1 and (b) is peak 2 .

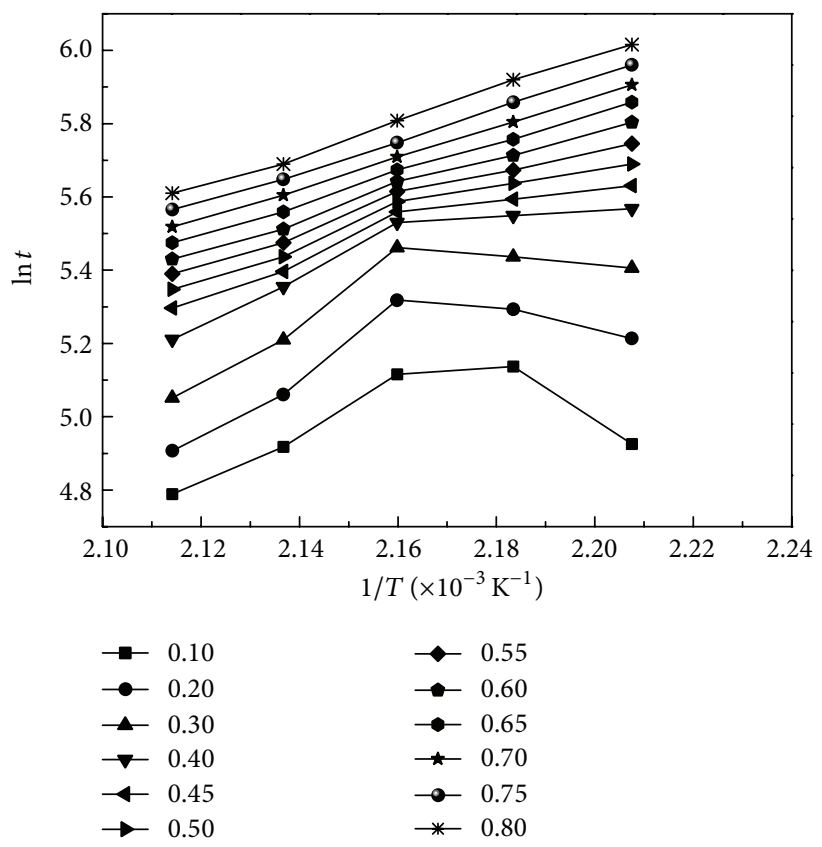

(a) Isoint method

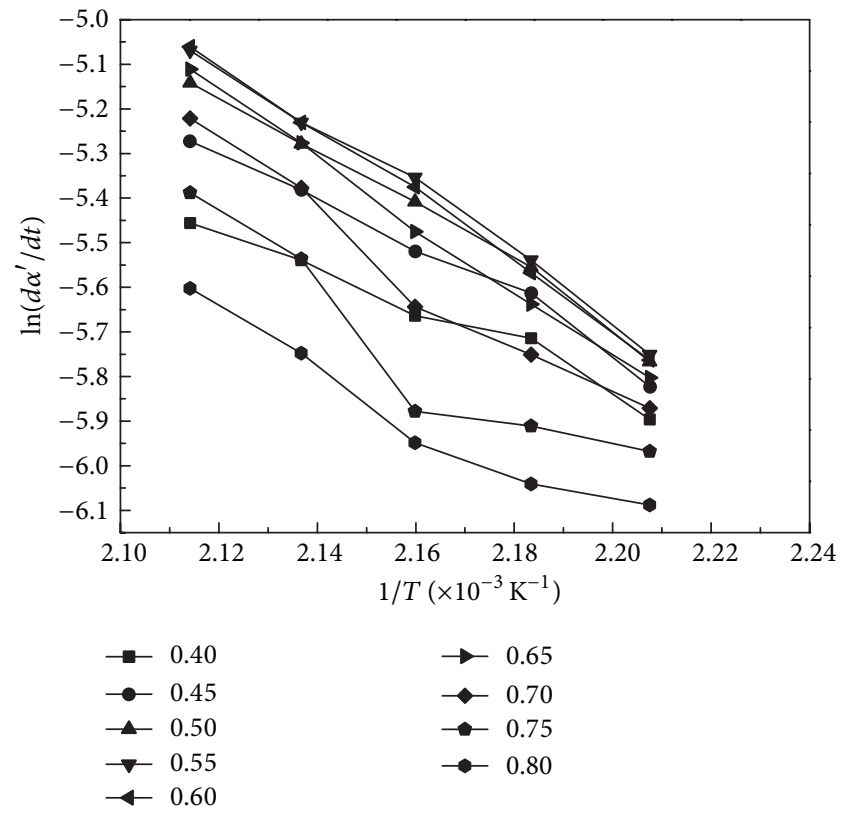

(b) FR method

FIGURE 12: Activation energy curves of isothermal curing processes of PMI by isoconversional methods.

conversion curves under low temperatures have a transitional stage which is strongly frequency-dependent, while this stage is not observed under high temperatures. (3) The fitting results to the relative increase of $E^{\prime}$ by Hsich's nonequilibrium thermodynamic fluctuation theory and Avrami equation are divided into two ranges. That the parameter $n$ in different range is different indicates that the growth mechanism of
$E^{\prime}$ is mutative. (4) Peak separation is made because of the change of the curing mechanism in order to study the isothermal curing process of PMI by isoconversional methods. The separation results are in good agreement with the assumption of isoconversional methods. The results studied by isoconversional method and Avrami equation show that the values and increase trends of activation energy 


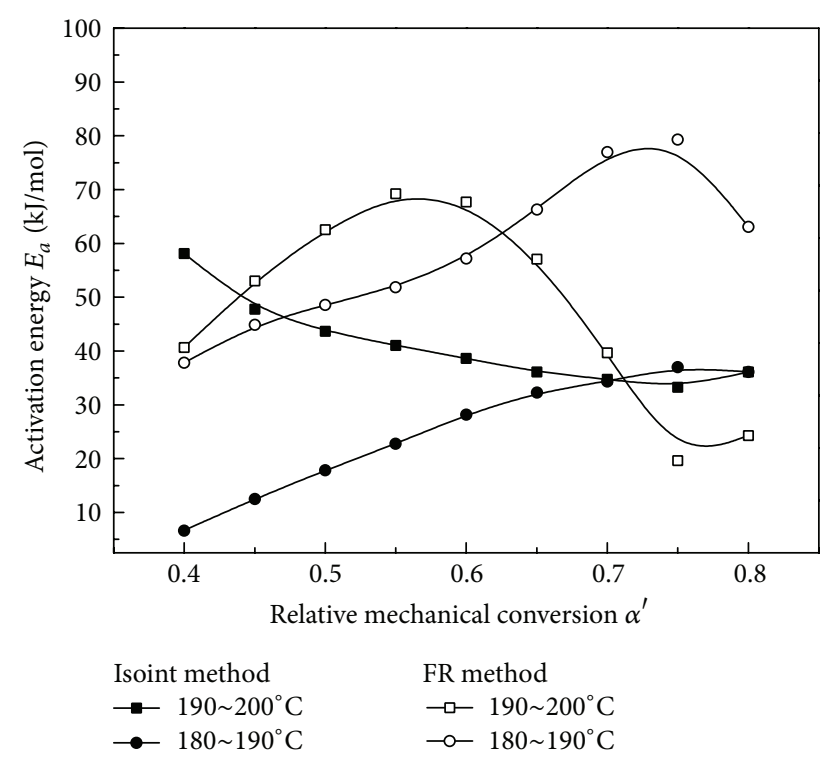

FIgURE 13: The evolution of activation energy during the curing process of PMI at different temperature ranges.

are different in two temperature ranges, which suggests that the curing mechanism probably has changed.

\section{Conflict of Interests}

The authors declare that there is no conflict of interests regarding the publication of this paper.

\section{Acknowledgments}

The authors greatly acknowledge a project funded by the Priority Academic Program Development of Jiangsu Higher Education Institution (35061101) and the Key Laboratory of Advanced Welding Technology of Jiangsu Province.

\section{References}

[1] F. S. Hermann, "PMI foam cores find further applications," Reinforced Plastics, vol. 4, pp. 36-38, 2000.

[2] F. S. Hermann, "PMI rigid foam plastics," Kunststoffe, vol. 4, pp. 32-33, 1999.

[3] H. F. Seibert, "Applications for PMI foams in aerospace sandwich structures," Reinforced Plastics, vol. 50, no. 1, pp. 44-48, 2006.

[4] L. D. McGarva and B. T. Åström, "Experimental investigation of compression moulding of glass/PA 12-PMI foam core sandwich components," Composites Part A: Applied Science and Manufacturing, vol. 30, no. 10, pp. 1171-1185, 1999.

[5] P. V. Kornienko, K. V. Shirshin, and Y. P. Gorelov, "Preparation of foamed polymethacrylimide structural materials from crosslinked copolymers of acrylonitrile and methacyrlic acid," Russian Journal of Applied Chemistry, vol. 85, no. 11, pp. 1748-1752, 2012.

[6] P. Stein, H. Seibert, L. Maier et al., "Method for producing polymethacrylimide foams," US 7169339B2, 2007.
[7] W. Geyer, H. Seibert, and S. Servaty, "Process for the produation of polymethacrylimide foam materials," US4928459, 1999.

[8] S. Servaty, W. Geyer, N. Rau et al., "Method for producing block-shape polymethacrylimide foamed materials," Tech. Rep. US6670405B1, 2003.

[9] J. Scherble, W. Geyer, H. Seibert et al., "Thermostable microporous polymethacrylimide foams," US20070077442A1, 2007.

[10] C. S. Chern and G. W. Poehlein, "A kinetic model for curing reactions of epoxides with amines," Polymer Engineering and Science, vol. 27, no. 11, pp. 788-795, 1987.

[11] V. M. González-Romero and N. Casillas, "Isothermal and temperature programmed kinetic studies of thermosets," Polymer Engineering and Science, vol. 29, no. 5, pp. 295-301, 1989.

[12] R. R. Corsetti, T. Neumeyer, M. May, D. Jandrey, V. Altstaedt, and N. S. M. Cardozo, "Modeling and estimation of parameters for the curing of an epoxy/amine system," Polymer Testing, vol. 32, no. 4, pp. 647-654, 2013.

[13] D. Santiago, X. Fernández-Francos, X. Ramis, J. M. Salla, and M. Sangermano, "Comparative curing kinetics and thermalmechanical properties of DGEBA thermosets cured with a hyperbranched poly(ethyleneimine) and an aliphatic triamine," Thermochimica Acta, vol. 526, no. 1-2, pp. 9-21, 2011.

[14] X. Ramis, A. Cadenato, J. M. Morancho, and J. M. Salla, "Curing of a thermosetting powder coating by means of DMTA, TMA and DSC," Polymer, vol. 44, no. 7, pp. 2067-2079, 2003.

[15] P. W. K. Lam, H. P. Plaumann, and T. Tran, "An improved kinetic model for the autocatalytic curing of styrene-based thermoset resins," Journal of Applied Polymer Science, vol. 41, no. 11-12, pp. 3043-3057, 1990.

[16] M. Pollard and J. L. Kardos, "Analysis of epoxy resin curing kinetics using the Avrami theory of range change," Polymer Engineering and Science, vol. 27, no. 11, pp. 829-836, 1987.

[17] M. G. Lu, M. J. Shim, and S. W. Kim, “The macrokinetic model of thermosetting polymers by phase-change theory," Materials Chemistry and Physics, vol. 56, no. 2, pp. 193-197, 1998.

[18] S.-W. Kim, M.-G. Lu, and M.-J. Shim, "The isothermal cure kinetic of epoxy/amine system analyzed by phase change theory," Polymer, vol. 30, no. 2, pp. 90-94, 1998.

[19] M. G. Lu, M. J. Shim, and S. W. Kim, "Dynamic DSC characterization of epoxy resin by means of the Avrami equation," Journal of Thermal Analysis and Calorimetry, vol. 58, no. 3, pp. 701-709, 1999.

[20] A. L. Daniel-da-Silva, J. C. M. Bordado, and J. M. MartínMartínez, "Use of isoconversional methods to analyze the cure kinetics of isocyanate-ended quasi-prepolymers with water," Journal of Applied Polymer Science, vol. 104, no. 2, pp. 1049-1057, 2007.

[21] S. Li, E. Vuorimaa, and H. Lemmetyinen, "Application of isothermal and model-free isoconversional modes in DSC measurement for the curing process of the PU system," Journal of Applied Polymer Science, vol. 81, no. 6, pp. 1474-1480, 2001.

[22] F. Dimier, N. Sbirrazzuoli, B. Vergnes, and M. Vincent, "Curing kinetics and chemorheological analysis of polyurethane formation," Polymer Engineering and Science, vol. 44, no. 3, pp. 518527, 2004.

[23] G. C. Stevens, "Cure kinetics of a high epoxide/hydroxyl groupratio bisphenol A epoxy resin-anhydride system by infrared absorption spectroscopy," Journal of Applied Polymer Science, vol. 26, no. 12, pp. 4279-4297, 1981. 
[24] R. Q. Chen, J. S. Chen, C. Q. Zhang, and M. R. Kessler, "Rapid room-temperature polymerization of bio-based multiaziridinecontaining compounds," RSC Advances, vol. 5, no. 2, pp. 15571563, 2015.

[25] C. Q. Zhang, Y. Xia, R. Q. Chen, S. Huh, P. A. Johnston, and M. R. Kessler, "Soy-castor oil based polyols prepared using a solvent-free and catalyst-free method and polyurethanes therefrom," Green Chemistry, vol. 15, no. 6, pp. 1477-1484, 2013.

[26] M.-W. Wang, C.-T. Lee, and M.-S. Lin, "Curing behaviour of compatible interpenetrating polymer networks based on epoxy and methacrylated epoxy," Polymer International, vol. 44, no. 4, pp. 503-509, 1997.

[27] J. Jakobsen, M. Jensen, and J. H. Andreasen, "Thermomechanical characterisation of in-plane properties for CSM Eglass epoxy polymer composite materials-Part 1: thermal and chemical strain," Polymer Testing, vol. 32, no. 8, pp. 1350-1357, 2013.

[28] G. R. Saad, E. E. Abd Elhamid, and S. A. Elmenyawy, "Dynamic cure kinetics and thermal degradation of brominated epoxy resin-organoclay based nanocomposites," Thermochimica Acta, vol. 524, no. 1-2, pp. 186-193, 2011.

[29] M.-K. Um, I. M. Daniel, and B.-S. Hwang, "A study of cure kinetics by the use of dynamic differential scanning calorimetry," Composites Science and Technology, vol. 62, no. 1, pp. 29-40, 2002.

[30] G. Schroeder, W. Gaenzler, and W. Bitsch, "Foamable synthetic resin compositions," US3627711, 1971.

[31] G. Schroeder, “Fomable polymer material," US4187353, 1980.

[32] F. Boardman, "Process for the preparation of polyimides," US3632797, 1972.

[33] S. Eugene, Barabas, and A. Klein, "Preparation of linear cyclic polyimides foam lattices," US4169924, 1979.

[34] E. A. Flexman, "Process for preparing imidized acrylic polymers," UB2101139, 1982.

[35] S. Jonas, G. Werner, S. Hermann et al., "Thermally stable, microporous polymethacrylimide foams," DEl0350971A1, 2005.

[36] S. Dalton, F. Heatley, and P. M. Budd, "Thermal stabilization of polyacrylonitrile fibres," Polymer, vol. 40, no. 20, pp. 5531-5543, 1999.

[37] Y. Yuan, C. Dazhu, H. Pingsheng, and Y. Haiyang, "Cure behavior of epoxy resin/CdS/2,4-EMI nanocomposites investigated by dynamic torsional vibration method (DTVM)," Polymer Bulletin, vol. 57, no. 2, pp. 219-230, 2006.

[38] C. Q. Zhang, S. A. Madbouly, and M. R. Kessler, "Biobased polyurethanes prepared from different vegetable oils," ACS Applied Materials and Interfaces, vol. 7, no. 2, pp. 1226-1233, 2014.

[39] S. R. White, P. T. Mather, and M. J. Smith, "Characterization of the cure-state of DGEBA-DDS epoxy using ultrasonic, dynamic mechanical, and thermal probes," Polymer Engineering and Science, vol. 42, no. 1, pp. 51-67, 2002.

[40] J. K. Gillham, "The TBA torsion pendulum: a technique for characterizing the cure and properties of thermosetting systems," Polymer International, vol. 44, no. 3, pp. 262-276, 1997.

[41] J. López, C. Ramírez, A. Torres et al., "Isothermal curing by dynamic mechanical analysis of three epoxy resin systems: gelation and vitrification," Journal of Applied Polymer Science, vol. 83, no. 1, pp. 78-85, 2002.

[42] L. Núez, F. Fraga, A. Castro, M. R. Núez, and M. Villanueva, "TTT cure diagram for an epoxy system diglycidyl ether of bisphenol A/1,2 diamine cyclohexane/calcium carbonate filler," Polymer, vol. 42, no. 8, pp. 3581-3587, 2001.
[43] S.-B. Shim, J. C. Seferis, Y. S. Eom, and Y. T. Shim, “Thermal characterization and comparison of structural prepregs with different cure temperatures," Thermochimica Acta, vol. 291, no. 1-2, pp. 73-79, 1997.

[44] B.-D. Park and J.-W. Kim, "Dynamic mechanical analysis of urea-formaldehyde resin adhesives with different formaldehyde-to-urea molar ratios," Journal of Applied Polymer Science, vol. 108, no. 3, pp. 2045-2051, 2008.

[45] L. Núñez, F. Fraga, A. Castro, M. R. Núñez, and M. Villanueva, "Effects of diffusion on the kinetic study of an epoxy system diglycidyl ether of bisphenol A/1,2-diamine cyclohexane/calcium carbonate filler," Journal of Applied Polymer Science, vol. 77, no. 10, pp. 2285-2295, 2000.

[46] S. Y. H. Hsich, "Kinetic model of cure reaction and filler effect," Journal of Applied Polymer Science, vol. 27, no. 9, pp. 3265-3277, 1982.

[47] C. Q. Zhang, Y. Z. Li, R. Q. Chen, and M. R. Kessler, "Polyurethanes from solvent-free vegetable oil-based polyols," ACS Sustainable Chemistry and Engineering, vol. 2, no. 10, pp. 24652476, 2014.

[48] S. Vyazovkin and N. Sbirrazzuoli, "Isoconversional kinetic analysis of thermally stimulated processes in polymers," Macromolecular Rapid Communications, vol. 27, no. 18, pp. 1515-1532, 2006.

[49] S. Vyazovkin, "Evaluation of activation energy of thermally stimulated solid-state reactions under arbitrary variation of temperature," Journal of Computational Chemistry, vol. 18, no. 3, pp. 393-402, 1997.

[50] S. Vyazovkin and N. Sbirrazzuoli, "Kinetic analysis of isothermal cures performed below the limiting glass transition temperature," Macromolecular Rapid Communications, vol. 21, no. 2, pp. 85-90, 2000.

[51] P. I. Karkanas and I. K. Partridge, "Cure modeling and monitoring of epoxy/amine resin systems. I. Cure kinetics modeling," Journal of Applied Polymer Science, vol. 77, no. 7, pp. 1419-1431, 2000. 

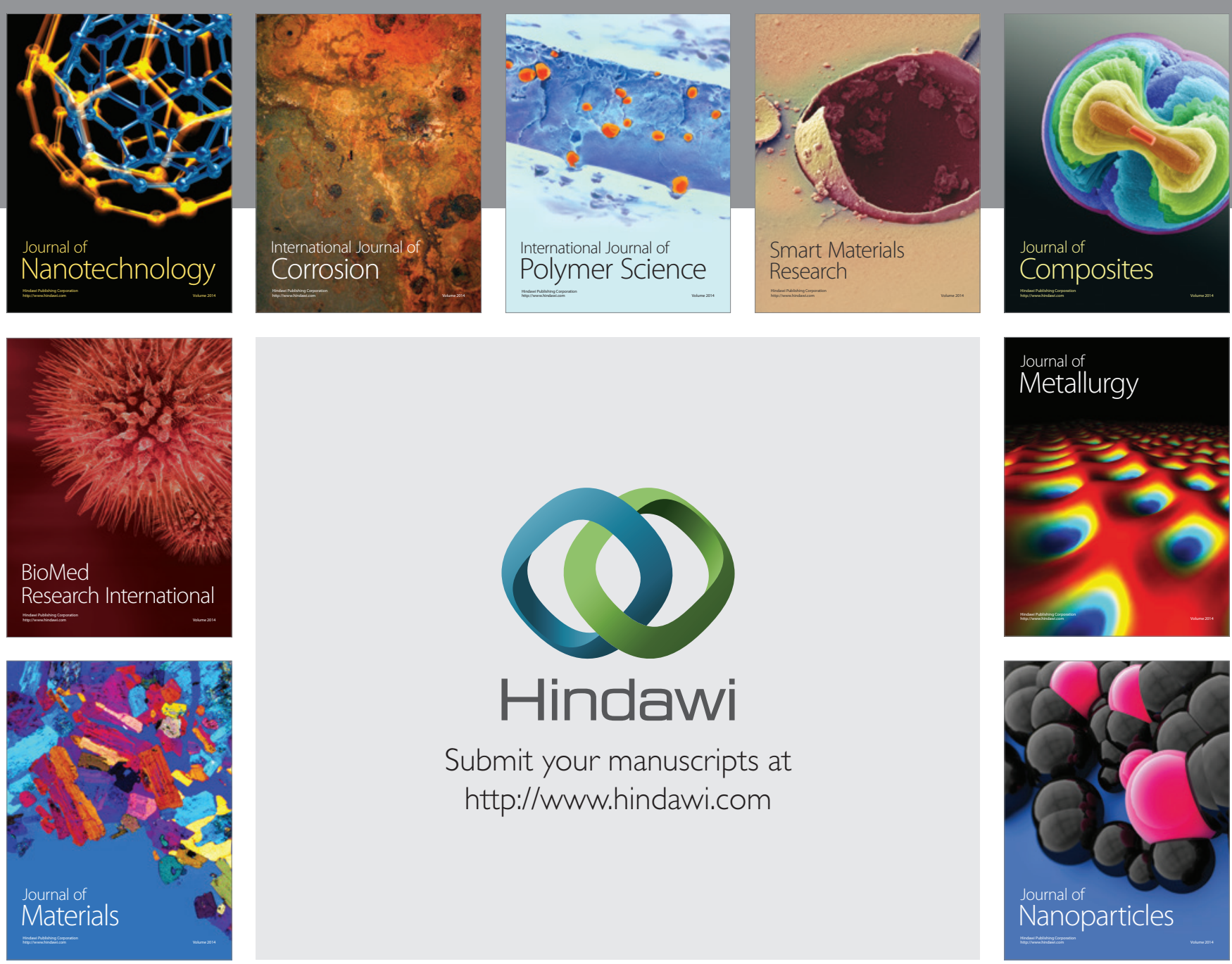

Submit your manuscripts at http://www.hindawi.com
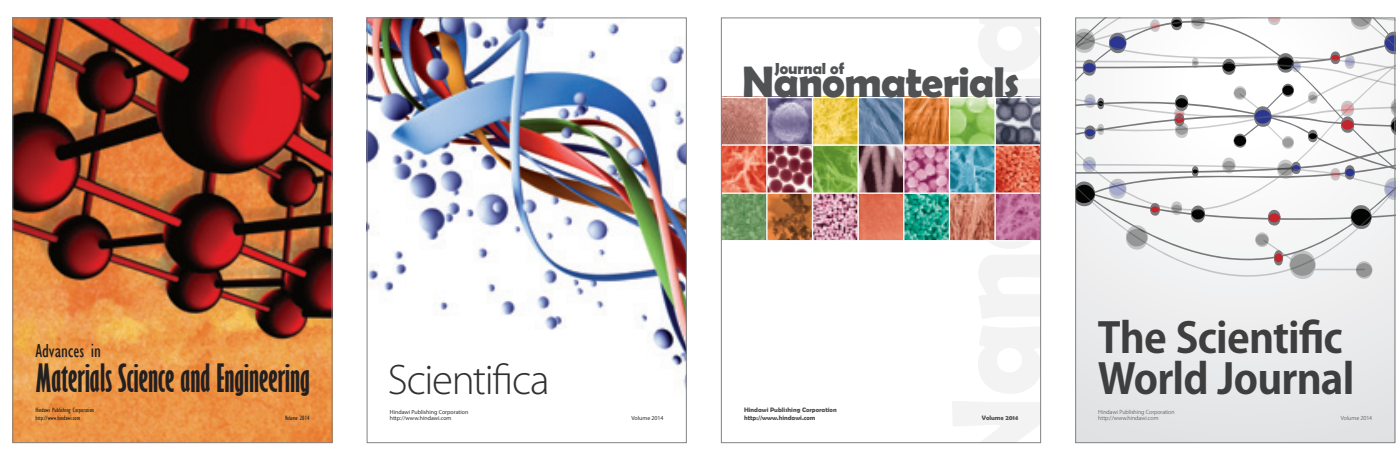

\section{The Scientific World Journal}
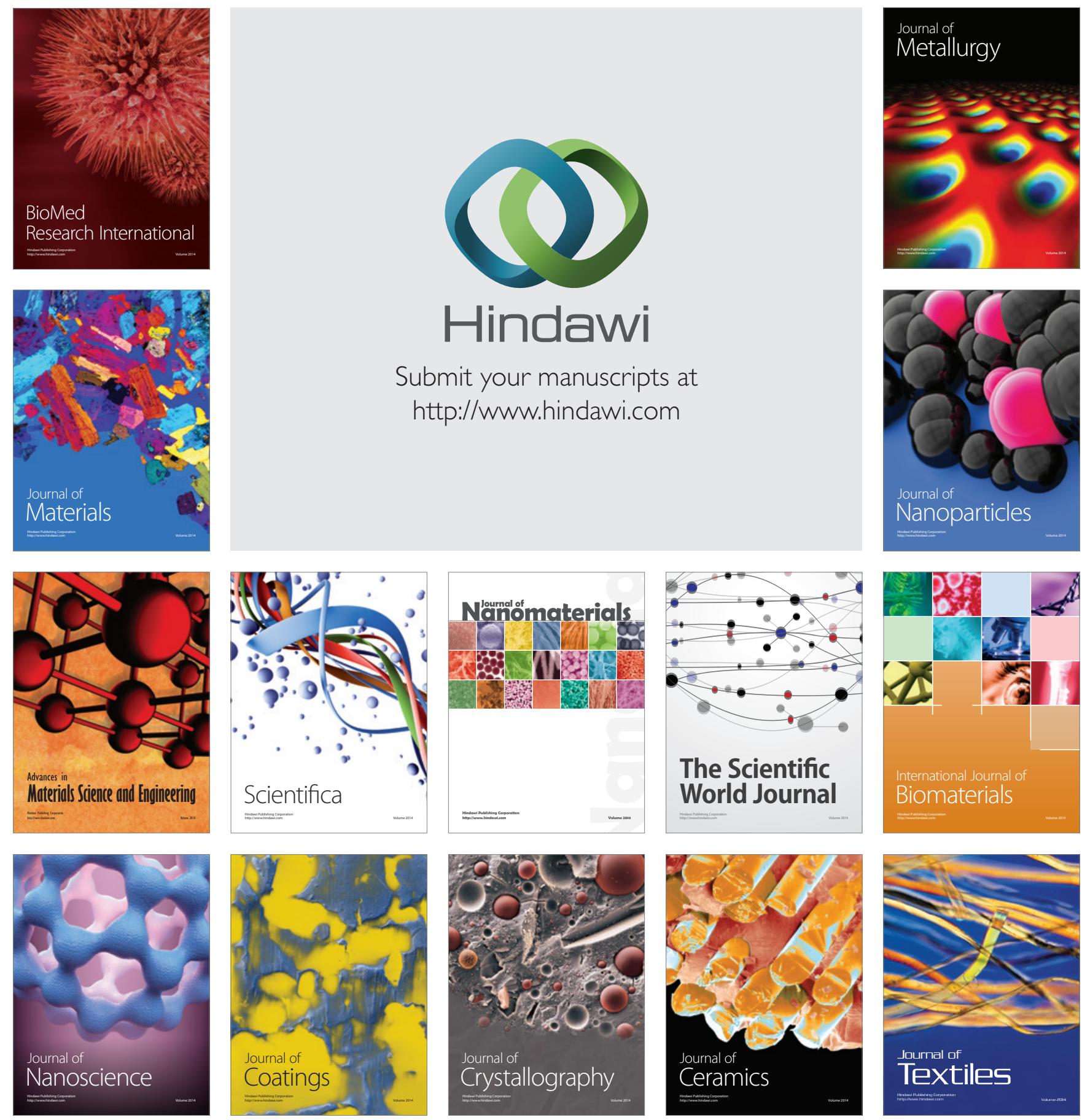